\title{
Phase Transfer Catalysis of Henry and Darzens Reactions
}

\author{
Layla Mhamdi ${ }^{1}$, Hafedh Bohli ${ }^{1}$, Younes Moussaoui ${ }^{1,2}$, Ridha ben Salem ${ }^{{ }^{*}}$ \\ ${ }^{1}$ Physical Organic Chemistry Laboratory, Science Faculty of Sfax, Sfax University, Sfax, Tunisia \\ ${ }^{2}$ Science Faculty of Gafsa, Gafsa University, Zarroug City, Gafsa, Tunisia \\ E-mail:y.moussaoui2@gmx.fr, Ridha.BenSalem@voila.fr \\ Received April 28, 2011; revised June 23, 2011; accepted August 16, 2011
}

\begin{abstract}
We describe in this work the influence of the addition of phase transfer catalyst in heterogeneous medium liquid/liquid on the output of the reactions of Darzens and Henry. It proves that the reaction of Darzens is favoured in the presence of low base such as $\mathrm{K}_{2} \mathrm{CO}_{3}$ and $\mathrm{Et}_{3} \mathrm{~N}$. Phase transfer catalysis is an efficient activation method in Darzens and Henry reactions. Thus, the Ethylene Diammonium Diacetate (EDD) has a comparable catalytic activity has that of quaternary ammonium salts in the reaction of Darzens.
\end{abstract}

Keywords: Darzens, Henry, Phase Transfer Catalysis, Mechanism

\section{Introduction}

The formation of a carbon-carbon bond is the fundamental reaction in organic synthesis [1-5]. To this respect, Henry [6-9] and Darzens [10-12] reactions can be considered as excellent tools to give access to multifunctional compounds $[13,14]$. The Darzens reaction gives $\alpha, \beta$-epoxy carbonyl compounds, whereas the Henry reaction leads to nitroaldols.

The Henry reaction [15] consists of the addition of a nitronate nucleophile on the double bond of a carbonyl compound. It proceeds usually at room temperature in the presence of a base to afford a $\beta$-nitroalcool. The preferred bases are alcali hydroxides [16], carbonates [17], bicarbonates [18] and alkali oxides. The reaction, however, is often carried out in protic media such as methanol or, even, water [19]. Henry adducts are very useful in organic synthesis as precursors for pharmaceutical and biological purposes $[20,21]$. In order to improve the efficiency of the reaction, new catalytic or non-catalytic methods have been divised such as alumina [22], potassium fluoride on alumina as support [23], lanthanides [24], high pressures [25] and microwaves [26]. In the same way, the Darzens reaction permits the synthesis of adducts simultaneously involving the formation of a carbon-carbon bond and a carbon-oxygen bond [12]. Several authors have tried to improve the enantioselectivity and the yields. Arai et al. [27] showed that the enantioselectivity of the Darzens reaction can be excellent when using a chiral auxiliary such as cinchonine, an alcaloid structurally close to quinine. Later on, the same group [28] introduced a phase transfer catalyst derived from cinchonine to synthetize Darzens products. In the same way, $\mathrm{Ku}$ et al. [29] reported the asymmetric synthesis of trans- $\alpha, \beta$-epoxysulfones by the catalytic phasetransfer Darzens reaction of chloromethyl phenyl sulfone with various aromatic aldehydes in the presence of the cinchona alkaloid-derived chiral phase-transfer catalysts.

In the goal to continue our works on the activation by the phase transfer catalysis of organic reactions such as: Wittig reaction [30], Baylis-Hillman reaction [31,32], Michael reaction [32,33], Knoevenagel reaction [34], Heck reaction [35,36]. In this work, we study the activation of Henry and Darzens reactions by means of phase transfer catalysis (PTC).

\section{Experimental}

\subsection{Henry Reaction}

Procedure A: A solution of nitroalkane $(7.5 \mathrm{mmol})$, solvent $(15 \mathrm{~mL})$, and base $(5 \mathrm{mmol})$ was introduced in a $25 \mathrm{~mL}$ flask equipped with a magnetic stirrer. $5 \mathrm{mmol}$ of carbonyl compound was added. The mixture was stirred during $24 \mathrm{~h}$ at ambient temperature. The organic phase was extracted with diethyl ether. When the carbonyl compound was an aldehyde, the organic phase was washed with a saturated solution of anhydrous sodium hydrogenosulfite to remove the unreacted aldehyde. The organic phase was dried over anhydrous sodium sulphate. After evaporation of the solvent the product was purified on silicagel column chromatography with hexane-ether 
mixtures as eluent.

Procedure B: As procedure A with addition of 2 mmol of the phase transfer catalyst.

\subsection{Darzens Reaction}

Procedure C: A solution of $\alpha$-chloroester or $\alpha$-chloroaacid or $\alpha$-chloronitrile $(3.6 \mathrm{mmol})$, solvent $(15 \mathrm{~mL})$, base $(3.6 \mathrm{mmol})$ was introduced in a $25 \mathrm{~mL}$ flask equipped with a magnetic stirrer. $3 \mathrm{mmol}$ of carbonyl compound was added. The mixture was stirred during $24 \mathrm{~h}$ at ambient temperature. The organic phase was extracted with diethyl ether and dried over anhydrous sodium sulphate. After evaporation of the solvent the product was purified on silicagel column chromatography with hexane-ether mixtures as eluent.

Procedure D: As procedure $\mathrm{C}$ with tetrahydrofurane as solvent and potassium hydroxide as the base with addition of $2 \mathrm{mmol}$ of the phase transfer catalyst.

\subsection{Synthesis of Ethylene Diammonium Diacetate (EDD)}

Ethylene diamine $(3 \mathrm{~g})$ in anhydrous diethylether was introduced in a $50 \mathrm{~mL}$ flask. The flask was immersed into a liquid bath maintained at $35^{\circ} \mathrm{C}$. Then, glacial acetic acid $(6 \mathrm{~g})$ was added. The mixture was stirred until boiling of ether. After $24 \mathrm{~h}$ cristallization occurred. The solid product was filtered and washed with ether. Finally, it was recrystallized in methanol.

\subsection{Recording of Spectra}

${ }^{1} \mathrm{H}(300 \mathrm{MHz})$ and ${ }^{13} \mathrm{C}(75 \mathrm{MHz}) \mathrm{NMR}$ spectra are recorded on a Bruker spectrometer in DMSO- $d_{6}$, with tetramethysilane as internal reference.

The products were analysed by GC-MS (HewlettPackard computerised system consisting of a 5890 gas chromatograph coupled to a $5971 \mathrm{~A}$ mass spectrometer) ionisation mode used was electronic impact at $70 \mathrm{eV}$.

Microanalyses were performed using a C, H, N Analyzer Model 185 from Hewlett-Packard. I.R. spectra are recorded in $\mathrm{KBr}$ on a Bruker Tensor 27 spectrometer in the range $4000-400 \mathrm{~cm}^{-1}$.

All the products were confirmed by comparing their IR, MS, ${ }^{1} \mathrm{H}$ NMR and ${ }^{13} \mathrm{C}$ NMR data with literature data $[9,10,12,37,38]$.

\section{Results and Discussion}

\subsection{Henry Reaction}

Effect of the base:

We have examined the nature of the base in the Henry reaction involving benzaldehyde and various nitroalkanes in aqueous solution (Table 1).

Inspection of the results of Table 1 shows that the reactivity is modest in the presence of bases such as triethylamine and weak in the presence of carbonate anions such as $\mathrm{K}_{2} \mathrm{CO}_{3}$. There is no reaction with sodium alcoolates.

This may be explained by the formation of secondary products issued from Cannizzaro reactions or hydrolysis in the presence of alcoolates on the contrary of reactions involving triethylamine or alkali carbonates. The results are in agreement with those of Zhou et al. [39] who found that Henry reaction of aromatic and aliphatic aldehydes with nitromethane is promoted by triethylamine in water.(Figure 1.)

Effect of the carbonyl compound:

The effect of the carbonyl compound was studied in a next step using nitromethane and various carbonyl compounds (Figure 2, Table 2).

As shown in Table 2, the reaction does not occur with ketones. Apparently this is due to the very weak reactivity of ketones toward the carbanion formed by deprotonation of nitromethane. Steric effects and the positive inductive effect lead in the case of ketones to a reduction

Table 1. Effect of the base in the Henry reaction.

\begin{tabular}{|c|c|c|c|c|}
\hline $\mathrm{R}^{1}$ & $\mathrm{R}^{2}$ & Product & Base & Yield (\%) \\
\hline \multirow{12}{*}{$\mathrm{H}$} & \multirow{4}{*}{$\mathrm{H}$} & \multirow{4}{*}{$1 \mathrm{a}$} & $\mathrm{CH}_{3} \mathrm{ONa}$ & 0 \\
\hline & & & EtONa & 0 \\
\hline & & & $\mathrm{Et}_{3} \mathrm{~N}$ & 46 \\
\hline & & & $\mathrm{K}_{2} \mathrm{CO}_{3}$ & 21 \\
\hline & \multirow{4}{*}{$\mathrm{CH}_{3}$} & \multirow{4}{*}{$1 b$} & $\mathrm{CH} 3 \mathrm{ONa}$ & 0 \\
\hline & & & EtONa & 0 \\
\hline & & & $\mathrm{Et}_{3} \mathrm{~N}$ & 42 \\
\hline & & & $\mathrm{K}_{2} \mathrm{CO}_{3}$ & 18 \\
\hline & \multirow{4}{*}{$\mathrm{C}_{2} \mathrm{H}_{5}$} & \multirow{4}{*}{$1 \mathrm{c}$} & $\mathrm{CH}_{3} \mathrm{ONa}$ & 0 \\
\hline & & & EtONa & 0 \\
\hline & & & $\mathrm{Et}_{3} \mathrm{~N}$ & 47 \\
\hline & & & $\mathrm{K}_{2} \mathrm{CO}_{3}$ & 24 \\
\hline \multirow{4}{*}{$\mathrm{CH}_{3}$} & \multirow{4}{*}{$\mathrm{CH}_{3}$} & \multirow{4}{*}{$1 d$} & $\mathrm{CH}_{3} \mathrm{ONa}$ & 0 \\
\hline & & & EtONa & 0 \\
\hline & & & $\mathrm{Et}_{3} \mathrm{~N}$ & 32 \\
\hline & & & $\mathrm{K}_{2} \mathrm{CO}_{3}$ & 17 \\
\hline
\end{tabular}

Procedure A

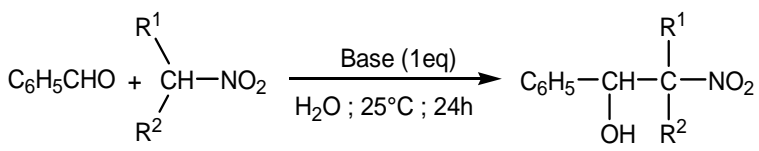

Figure 1. Henry reaction of benzaldehyde with nitroalkane.

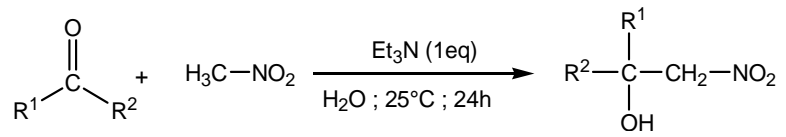

Figure 2. Henry reaction of nitromethane with carbonyl compound. 
Table 2. Effect of the carbonyl compound in the Henry reaction.

\begin{tabular}{cccc}
\hline $\mathrm{R}^{1}$ & $\mathrm{R}^{2}$ & Product & Yield (\%) \\
\hline $\mathrm{H}$ & $\mathrm{C}_{6} \mathrm{H}_{5}$ & $1 \mathrm{a}$ & 46 \\
$\mathrm{H}$ & $\mathrm{C}_{3} \mathrm{H}_{7}$ & $1 \mathrm{e}$ & 48 \\
$\mathrm{H}$ & $\mathrm{Cl}_{7}-\mathrm{C}_{6} \mathrm{H}_{4}$ & $1 \mathrm{f}$ & 54 \\
$\mathrm{CH}_{3}$ & $\mathrm{C}_{2} \mathrm{H}_{5}$ & $1 \mathrm{~g}$ & 0 \\
$\mathrm{CH}_{3}$ & $\mathrm{C}_{6} \mathrm{H}_{5}$ & $1 \mathrm{~h}$ & 0 \\
\multicolumn{2}{c}{$-\left(\mathrm{CH}_{2}\right)_{5^{-}}$} & $1 \mathrm{i}$ & 0 \\
& $-\left(\mathrm{CH}_{2}\right)_{4^{-}}$ & $1 \mathrm{j}$ & 0 \\
\hline
\end{tabular}

Procedure A.

of the electrophilicity of the carbon in the carbonyl group. This makes the attack of the resulting carbanion more difficult.

\section{Effect of phase transfer catalysis:}

In the following step we examined the nature of the phase transfer catalyst in Henry reactions involving various aldehydes and ketones.(Figure 3.)

The results of Table 3 show that

1) There is no reaction in the absence of PTC with $\mathrm{C5}$ and $\mathrm{C} 6$ cyclic ketones. With the addition of PTC catalysts, the reaction occurs in fair yields.

2) In the other reactions, the reaction occurs whatever the addition or not of phase transfer catalysts. The catalyst, however, leads to an improvement of yields. This can be explained by the stability of the reaction intermediate formed by the addition of the PT catalyst to the carbanion. Such intermediate inhibits any possible retro Henry reaction.

3) Among the quaternary ammonium salts listed in Table 3, the most appropriate seems to be Aliquat-336. The catalytic activity of the ammonium salt depends on

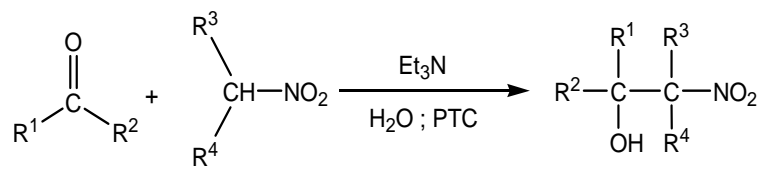

Figure 3. Henry reaction of nitroalkanes with carbonyl compounds.

Table 3. Effect of the PT catalysts in the Henry reaction.

\begin{tabular}{ccccccccc}
\hline & & & & \multirow{2}{*}{ Yield \% } \\
\cline { 6 - 9 } $\mathrm{R}^{1}$ & $\mathrm{R}^{2}$ & $\mathrm{R}^{3}$ & $\mathrm{R}^{4}$ & $\begin{array}{c}\text { Prod- } \\
\text { uct }\end{array}$ & & & & no \\
& & & & & PTC & TBAB TEBAC & $\begin{array}{c}\text { Aliquat } \\
-336\end{array}$ \\
\hline $\mathrm{C}_{6} \mathrm{H}_{5}$ & $\mathrm{H}$ & $\mathrm{H}$ & $\mathrm{H}$ & $1 \mathrm{a}$ & 46 & 52 & 53 & 70 \\
$\mathrm{C}_{6} \mathrm{H}_{5}$ & $\mathrm{H}$ & $\mathrm{H}$ & $\mathrm{CH}_{3}$ & $1 \mathrm{~b}$ & 36 & - & 55 & 68 \\
$\mathrm{C}_{3} \mathrm{H}_{7}$ & $\mathrm{H}$ & $\mathrm{H}$ & $\mathrm{H}$ & $1 \mathrm{c}$ & 48 & 51 & 60 & 72 \\
$\mathrm{C}_{6} \mathrm{H}_{5}$ & $\mathrm{H}$ & $\mathrm{CH}_{3}$ & $\mathrm{CH}_{3}$ & $1 \mathrm{~d}$ & 16 & - & 56 & 39 \\
$\left(\mathrm{CH}_{2}\right)_{5}$ & $\mathrm{H}$ & $\mathrm{H}$ & $1 \mathrm{i}$ & 0 & 17 & 22 & 44 \\
$\left(\mathrm{CH}_{2}\right)_{4}$ & $\mathrm{H}$ & $\mathrm{H}$ & $1 \mathrm{j}$ & 0 & 12 & 24 & 47 \\
$\mathrm{C}_{3} \mathrm{H}_{7}$ & $\mathrm{H}$ & $\mathrm{H}$ & $\mathrm{CH}_{3}$ & $1 \mathrm{k}$ & 38 & - & 63 & 41 \\
$\mathrm{C}_{3} \mathrm{H}_{7}$ & $\mathrm{H}$ & $\mathrm{CH}$ & $\mathrm{CH}_{3}$ & 11 & 18 & - & - & 42 \\
\hline
\end{tabular}

Procedure B. TBAB: bromure de tétrabutylammonium; TEBAC: chlorure de benzyltriéthylammonium; Aliquat-336: chlorure de méthyltrioctylammonium. the structure of the alkyl or aryl groups on the nitrogen atom and, also, on the nature of the counter-ion. It may also be noticed that the presence of a lipophilic group (this is the case of Aliquat-336) is beneficial for the formation of the Henry adduct as it facilitates the nucleophilic attack on the aldehyde [31].

4) At last, the yield depends on the nature of the anion associated with the ammonium cation. It is higher with tetrabutylammonium chloride than with the corresponding bromide. The same result was also found by D'Incan in his study examining the effect of the phase transfer agent on the Horner-Emmons reaction between benzaldehyde and 1-cyanoethyl diethyphosphonate [40].

We propose the following mechanism of the Henry reaction involving benzaldehyde and nitromethane under PTC conditions (Figure 4).

\subsection{Darzens Reaction}

\section{Effect of solvent:}

The effect on the nature of the solvent in the Darzens reactions was studied in condensations between benzaldehyde and a $\alpha$-chloroester, $\alpha$-chloroacid or $\alpha$-chloroacetonitrile in the presence of potassium hydroxide as the base. (Figure 5.)

According to the results of Table 4, there is no reaction in aqueous solution in reactions involving $\alpha$-chloroesters or $\alpha$-chloroacetonitrile. In organic phase, the reactivity remains low. With an acidic $\alpha$-chloroacetate, however, there is no reactivity at all whatever the medium, aqueous or organic. This may be ascribed to a decomposition of the acidic function supported by the release of carbon dioxide.

Tetrahydrofurane seems to be the most adequate solvent for the Darzens reactions between benzaldehyde and

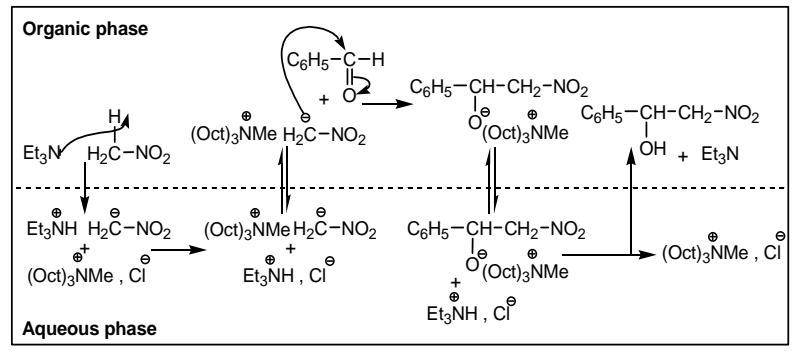

Figure 4. Mechanism of the Henry reaction between nitromethane and benzaldehyde under PTC conditions (liquid-liquid heterogeneous catalysis).

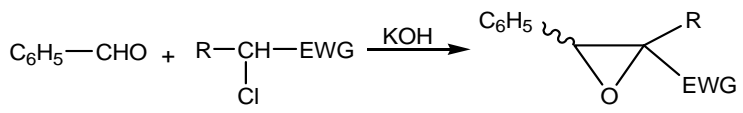

Figure 5. Darzens reaction of benzaldehyde with a $\alpha$-chloroester, $\alpha$-chloroacid or $\alpha$-chloroacetonitrile. 
Table 4. Effect of the base in the Henry reaction.

\begin{tabular}{|c|c|c|c|c|}
\hline $\mathrm{R}$ & EWG & Product & Solvent & Yield (\%) \\
\hline \multirow{9}{*}{$\mathrm{H}$} & \multirow{3}{*}{$\mathrm{CN}$} & \multirow{3}{*}{$2 a$} & T.H.F & 36 \\
\hline & & & $\mathrm{CH}_{2} \mathrm{Cl}_{2}$ & 22 \\
\hline & & & Water & 0 \\
\hline & \multirow{4}{*}{ COOEt } & \multirow{4}{*}{$2 b$} & T.H.F & 28 \\
\hline & & & $\mathrm{CH}_{2} \mathrm{Cl}_{2}$ & 18 \\
\hline & & & Water & 0 \\
\hline & & & T.H.F & 0 \\
\hline & \multirow{3}{*}{$\mathrm{COOH}$} & \multirow{3}{*}{$2 \mathrm{c}$} & $\mathrm{CH}_{2} \mathrm{Cl}_{2}$ & 0 \\
\hline & & & Water & 0 \\
\hline \multirow{3}{*}{$\mathrm{CH}_{3}$} & & & T.H.F & 21 \\
\hline & \multirow[t]{2}{*}{ COOEt } & \multirow[t]{2}{*}{$2 d$} & $\mathrm{CH}_{2} \mathrm{Cl}_{2}$ & 12 \\
\hline & & & Water & 0 \\
\hline
\end{tabular}

Procedure C

$\alpha$-chloroester or $\alpha$-chloroacetonitrile, in agreement with the results given by Wang et al. [12].

Effect of the base:

Using THF as the solvent we have studied the effect of the base in the Darzens reaction at ambient temperature (Figure 6).

Table 5 shows that the Darzens reaction of benzaldehyde and $\alpha$-chloroesters or $\alpha$-chloroacetonitrile is favoured in the presence of KOH. Sodium hydroxide, however, is not indicated. This is probably due to the opening of the epoxy cycle with $\mathrm{NaOH}$, a result also given by Wang et al. [12].

Effect of the carbonyl compound

From Table 6, we note that the Darzens reaction proceeds better with aldehydes than with ketones. The latter do not react with $\alpha$-chloroacetonitrile. This seems to be due to the weak reactivity of ketones toward the carbanion formed by deprotonation of $\alpha$-chloroacetonitrile. Steric

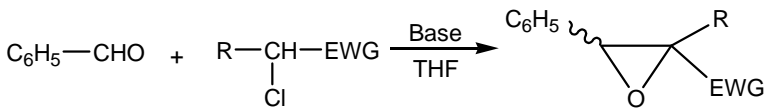

Figure 6. Darzens reaction: effect of the base.

Table 5. Effect of the base in the Darzens reaction.

\begin{tabular}{|c|c|c|c|c|}
\hline $\mathrm{R}$ & EWG & Product & Base & Yield (\%) \\
\hline \multirow{13}{*}{$\mathrm{H}$} & \multirow{4}{*}{$\mathrm{CN}$} & \multirow{4}{*}{$2 a$} & $\mathrm{~K}_{2} \mathrm{CO}_{3}$ & 16 \\
\hline & & & $\mathrm{NaOH}$ & 0 \\
\hline & & & $\mathrm{KOH}$ & 36 \\
\hline & & & $\mathrm{Et}_{3} \mathrm{~N}$ & 10 \\
\hline & & \multirow{4}{*}{$2 b$} & $\mathrm{~K}_{2} \mathrm{CO}_{3}$ & 12 \\
\hline & \multirow{4}{*}{ COOEt } & & $\mathrm{NaOH}$ & 0 \\
\hline & & & $\mathrm{KOH}$ & 28 \\
\hline & & & $\mathrm{Et}_{3} \mathrm{~N}$ & 12 \\
\hline & & \multirow{5}{*}{$2 \mathrm{c}$} & $\mathrm{K}_{2} \mathrm{CO}_{3}$ & 0 \\
\hline & \multirow{4}{*}{$\mathrm{COOH}$} & & $\mathrm{NaOH}$ & 0 \\
\hline & & & $\mathrm{KOH}$ & 0 \\
\hline & & & $\mathrm{Et}_{3} \mathrm{~N}$ & 13 \\
\hline & & & $\mathrm{K}_{2} \mathrm{CO}_{3}$ & 14 \\
\hline \multirow[t]{2}{*}{$\mathrm{CH}_{3}$} & COOEt & $2 d$ & $\mathrm{KOH}$ & 0 \\
\hline & & & $\mathrm{Et}_{3} \mathrm{~N}$ & 14 \\
\hline
\end{tabular}

Table 6. Effect of the carbonyl compound in the Darzens reaction.

\begin{tabular}{cccc}
\hline $\mathrm{R}^{1}$ & $\mathrm{R}^{2}$ & Product & Yield (\%) \\
\hline \multirow{2}{*}{$\mathrm{H}$} & $\mathrm{C}_{6} \mathrm{H}_{5}$ & $2 \mathrm{a}$ & 36 \\
& $\mathrm{C}_{3} \mathrm{H}_{7}$ & $2 \mathrm{e}$ & 32 \\
$\mathrm{CH}_{3}$ & $\mathrm{C}_{2} \mathrm{H}_{5}$ & $2 \mathrm{f}$ & 0 \\
\hline
\end{tabular}

effects and the inductive effect $(+\mathrm{I})$ lead in the case of ketones to a reduction of the electrophilic character of the carbon in the carbonyl group making the attack of the generated carbanion more difficult (Figure 7).

Effect of phase transfer catalysts

All the above results reveal that the yield in the investigated Darzens reactions is generally low. In order to improve such yields, we have turned to the use of phase transfer catalysts (Figure 8).

There is no reaction in the condensation between benzaldehyde and $\alpha$-chloroacetate even under PTC conditions (Table 7).

The addition of a phase transfer catalyst on the medium noticeably enhances the reactivity (Table 7). This may be ascribed to the exaltation of the nucleophilicity of the carbanion formed by the addition of the PTC catalyst on the carbanion (Figure 9).

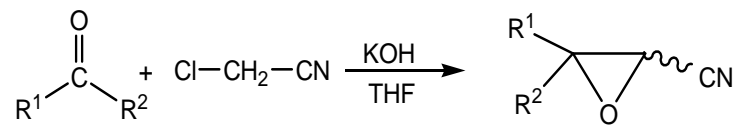

Figure 7. Darzens reaction of $\alpha$-chloroacetonitrile with various carbonyl compounds.

$$
\mathrm{C}_{6} \mathrm{H}_{5}-\mathrm{CHO}+\mathrm{Cl}-\mathrm{CH}_{2}-\mathrm{EWG} \underset{\mathrm{THF}}{\stackrel{\text { Base }}{\longrightarrow}} \stackrel{\mathrm{C}_{6} \mathrm{H}_{5}}{\underset{\mathrm{O}}{\sim}} \stackrel{\text { EWG }}{\sim}
$$

Figure 8. Effect of phase transfert catalyst in the Darzens reaction of benzaldehyde with $\alpha$-chloroacetonitrile, $\alpha-c h l-$ oroacetic acid and ethyl $\alpha$-chloro-acetic acid.

Table 7. Effect of PT catalyst in the Darzens reaction

\begin{tabular}{ccccc}
\hline \multirow{2}{*}{ EWG } & \multirow{2}{*}{ Product } & \multicolumn{3}{c}{ Yield \% } \\
\cline { 3 - 5 } & & no PTC & Aliquat-336 & EDD* \\
\hline CN & $2 \mathrm{a}$ & 36 & 60 & 64 \\
$\mathrm{COOEt}$ & $2 \mathrm{~b}$ & 28 & 41 & 48 \\
$\mathrm{COOH}$ & $2 \mathrm{c}$ & 0 & 0 & 0 \\
\hline
\end{tabular}

Procedure D. *EDD: Ethylene Diammonium Diacetate

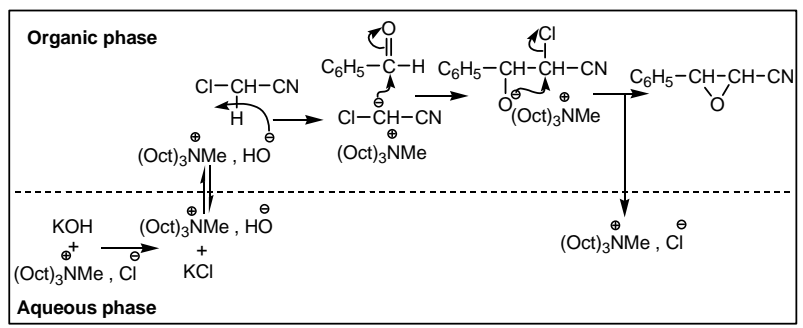

Figure 9. Mechanism of the Darzens reaction involving benzaldehyde and $\alpha$-chloroacetonitrile under PTC conditions. 


\section{Conclusions}

The anionic activation in Henry and Darzens reactions has been achieved by the addition of quaternary ammonium salts leading to an exaltation of the reactivity of the generated anions. The addition of a phase transfer catalyst in the reaction medium leads to an increase in the yield for the Henry reaction involving nitromethane and various ketones as well as a remarkable reactivity in the Darzens reaction. On the contrary, there is no reaction with a $\alpha$-chloroacetate acid whatever the medium, even under PTC conditions.

\section{References}

[1] J. Franzen, J. Lofstedt, J. Falk and J. E. Backvall, "Stereoselective Palladium-Catalyzed Carbocyclization of Allenic Allylic Carboxylates," Journal of American Chemical Society, Vol. 125, No. 46, 2003, pp. 14140-14148. doi:10.1021/ja037398u

[2] S. M. Ma, S. C. Yu and S. H. Yin, "Studies on $\mathrm{K}_{2} \mathrm{CO}_{3}$ Catalyzed 1,4-Addition of 1,2-Allenic Ketones with Diethyl Malonate: Controlled Selective Synthesis of $\beta, \gamma-$ Unsaturated Enones and $\alpha$-Pyrones," The Journal of Organic Chemistry, Vol. 68, No. 23, 2003, pp. 8996-9002. doi:10.1021/jo034633i

[3] C. A. Lin and F. T. Luo, "Polystyrene-Supported Recyclable Palladacycle Catalyst for Heck, Suzuki and Sonogashira Reactions," Tetrahedron Letters, Vol. 44, No. 41, 2003, pp. 7565-7568. doi:10.1016/j.tetlet.2003.08.069

[4] D. O. Jang and D. H. Cho, "N-Ethylpiperidine Hypophosphite Mediated Intermolecular Radical CarbonCarbon Bond Forming Reaction in Water," Synlett, Vol. 9, 2002, pp. 1523-1525.

[5] B. E. Maryanoff and A. B. Reitz, "The Wittig Olefination Reaction and Modifications Involving Phosphoryl-Stabilized Carbanions. Stereochemistry, Mechanism, and Selected Synthetic Aspects," Chemical Reviews, Vol. 89, No. 4, 1989, pp. 863-927. doi:10.1021/cr00094a007

[6] G. Rosini, R. Ballini, M. Petrini, E. Marotta and P. Righi, "Recent Progress in the Synthesis and Reactivity of Nitroketones," Organic Preparations and Procedures International, Vol. 22, No. 6, 1990, pp. 707-746. doi:10.1080/00304949009457902

[7] F. A. Luzzio, "The Henry Reaction: Recent Examples," Tetrahedron, Vol. 57, 2001, pp. 915-945.

[8] G. Klein, S. Pandiaraju and O. Reiser, "Activation of Nitroaldol Reactions by Diethylzinc and Amino Alcohols or Diamines as Promoters," Tetrahedron Letters, Vol. 43, No. 42, 2002, pp. 7503-7506. doi:10.1016/S0040-4039(02)01768-9

[9] T. Jiang, H. Gao, B. Han, G. Zhao, Y. Chang, W. Wu, L. Gao and G. Yang, "Ionic Liquid Catalyzed Henry Reactions," Tetrahedron Letters, Vol. 45, No. 12, 2004, pp. 2699-2701. doi:10.1016/j.tetlet.2004.01.129

[10] V. K. Aggarwal, G. Hynd, W. Picoul and J. L. Vasse,
"Highly Enantioselective Darzens Reaction of a Camphor-Derived Sulfonium Amide to Give Glycidic Amides and Their Applications in Synthesis," Journal of American Chemical Society, Vol. 124, No. 34, 2002, pp. $9964-$ 9965. doi:10.1021/ja0272540

[11] N. E. Maguire, A. B. McLaren and J. B. Sweeney, "Asymmetric Synthesis of Arylalanines via Asymmetric aza-Darzens (ADZ) Reaction," Synlett, Vol. 12, 2003, pp. 1898- 1900.

[12] Z. Wang, L. Xu, Z. Mu, C. Xia and H. Wang, "Efficient Darzens Condensation Reactions of Aromatic Aldehydes Catalyzed by Polystyrene-Supported Phase-Transfer Catalyst," Journal of Molecular Catalysis A: Chemical, Vol. 218, No. 2, 2004, pp. 157-160. doi:10.1016/j.molcata.2004.04.023

[13] K. Ohkata, J. Kimura, Y. Shinohara, R. Takagi and Y. Hiraga, "Asymmetric Darzens Condensation of Ketones with $\alpha$-Chloroacetates by Means of (-)-8-Phenylmenthyl Auxiliary," Chemical Communications, No. 21, 1996, pp 2411-2412. doi:10.1039/cc9960002411

[14] T. Takahashi, M. Muraoka, M. Capo and K. Koga, "Enantioselective Darzens Reaction: Asymmetric Synthesis of Trans-Glycidic Esters Mediated by Chiral Lithium Amides," Chemical \& Pharmaceutical Bulletin, Vol. 43, No. 10, 1995, pp. 1821-1823.

[15] R. Ballini and G. Bosica, "Nitroaldol Reaction in Aqueous Media: An Important Improvement of the Henry Reaction," The Journal of Organic Chemistry, Vol. 62, No. 2, 1997, pp. 425-427. doi:10.1021/jo961201h

[16] B. M. Vanderbilt and H. B. Hass, "Aldehyde-Nitroparaffin Condensation," Industrial \& Engineering Chemistry, Vol. 32, No. 1, 1940, pp. 34-38. doi:10.1021/ie50361a007

[17] L. W. Herman and J. W. Apsimon, "A Novel Intramolecularly Stabilized Nitronic Acid, 2-Aci-Nitro1,3-Propanediol," Tetrahedron Letters, Vol. 26, No. 11, 1985, pp. 1423-1424. doi:10.1016/S0040-4039(00)99061-0

[18] V. Simanek, V. Preininger, A. Klasek and J. Jurina, "The Structure and the Synthesis of Sevanine," Heterocycles, Vol. 4, No. 7, 1976, pp. 1263-1267. doi:10.3987/R-1976-07-1263

[19] A. S. Cavallo, H. Lapitajs, P. Buchert, A. Klein, S. Colonna and A. Manfredi, "Asymmetric Synthesis of Ephedrine Analogs," Journal of Organomettalic Chemistry, Vol. 330, 1987, pp. 357-363.

[20] D. Seebach, E. W. Colwin, F. Lehr and T. Weller, "Nitroaliphatic Compounds-Ideal Intermediates in Organic Synthesis," Chimia, Vol. 33, 1979, pp. 1-18.

[21] R. Royer, "Title of This Paper," Ann. Pharm. Fr., Vol. 41, No. *, 1983, pp. 299-311.

[22] G. Rossini, R. Ballini and P. Sorrenti, "Synthesis of 2-Nitroalkanols on Alumina Surfaces without Solvent: A Simple, Mild and Convenient Method," Synthesis, Vol. 12, 1983, pp. 1014-1016.

[23] J. M. Melot, F. Texier-Boullet and A. Foucaud, "Preparation and Oxidation of $\alpha$-Nitro Alcohols with Supported 
Reagents," Tetrahedron Letters, Vol. 27, No. 4, 1986, pp. 493-496. doi:10.1016/S0040-4039(00)85513-6

[24] H. Sasai, T. Suzuki, N. Itoh, S. Arai and M. Shibasaki, "Effects of Rare Earth Metals on the Catalytic Asymmetric Nitroaldol Reaction," Tetrahedron Letters, Vol. 34, No. 16,1993 , pp. 2657-2660. doi:10.1016/S0040-4039(00)77649-0

[25] K. Matsumoto, "Hochdrucksynthesen: Die Henry-Reaktion," Angewandte Chemie, Vol. 96, No. 8, 1984, p. 599. doi:10.1002/ange.19840960814

[26] R. S. Varma, R. Dahiya and S. Kumar, "Micro-WaveAssisted Henry Reaction: Solventless Synthesis of Conjugated Nitroalkenes," Tetrahedron Letters, Vol. 38, No. 29, 1997, pp. 5131-5134. doi:10.1016/S0040-4039(97)01093-9

[27] S. Arai and T. Shiori, "Catalytic Asymmetric Darzens Condensation under Phase-Transfer-Catalyzed Conditions," Tetrahedron Letters, Vol. 39, No. 15, 1998, pp. 2145-2148. doi:10.1016/S0040-4039(98)00081-1

[28] S. Arai, Y. Shirai, T. Ishida and T. Shioiri, "PhaseTransfer-Catalyzed Asymetric Darzens Reaction," Tetrahedron, Vol. 55, 1999, pp. 6375-6386.

[29] J.-M. Ku, M.-S. Yoo, H.-G. Park, S.-S. Jew and B.-S. Jeong "Asymmetric Synthesis of a,b-Epoxysulfones via Phase-Transfer Catalytic Darzens Reaction," Tetrahedron, Vol. 63, 2007, pp. 8099-8103.

[30] Y. Moussaoui, K. Saïd and R. Ben Salem, "Anionic Activation of the Wittig Reaction Using a Solid-Liquid Phase Transfer: Examination of the Medium-, Temperature-, Base- and Phase-Transfer Catalyst Effects," ARKIVOC, (XII), 2006, pp. 1-22.

[31] Y. Moussaoui and R. ben Salem, "Etude de L'activation des réActions Anioniques par la Catalyse par Transfert de Phase," Journal Société Chimique Tunisie, Vol. 5, 2003, pp. 255-263.

[32] Y. Moussaoui and R. ben Salem, "Catalyse par Transfert de Phase Solide/Liquide en L'absence de Solvant,"
Comptes Rendus Chimie, Vol. 10, No. 7, 2007, pp. 630636. doi:10.1016/j.crci.2006.11.004

[33] Y. Moussaoui and R. ben Salem, "Michael Additions of Nitroalkanes to Conjugated Ketones, Carboxylic Esters and Nitriles in Water and Biphasic Conditions (WaterDichloromethane)," Journal Société Chimique Tunisie, Vol. 11, 2009, pp. 37-43.

[34] Y. Moussaoui and R. ben Salem, "Catalyzed Knoevenagel Reactions on Inorganic Solid Supports: Application to the Synthesis of Coumarine Compounds," Comptes Rendus Chimie, Vol. 10, 2007, pp. 1162-1169.

[35] K. Saïd, Y. Moussaoui and R. ben Salem, "Heck Coupling Styrene with Aryl Halides Catalyzed by Palladium Complexes in Biphasic Media," Journal Société Chimique Tunisie, Vol. 11, 2009, pp. 59-67.

[36] K. Saï, Y. Moussaoui, M. Kammoun and R. ben Salem, "Ultrasonic Activation of Heck Type Reactions in the Presence of Aliquat-336," Ultrasonics Sonochemistry, Vol. 18, No. 1, 2011, pp. 23-27. doi:10.1016/j.ultsonch.2010.04.007

[37] J. M. Saa, F. Tur, J. Gonzalez and M. Vega, "Chiral Monometallic Lanthanide (III) Salt Complexes Are Arrayed Acid-Base Networks for Enantioselective Catalysis: A Direct, Nitroaldol (Henry) Reaction," Tetrahedron: Asymmetry, Vol. 17, No. 1, 2006, pp. 99-106. doi:10.1016/j.tetasy.2005.11.014

[38] B. M. Trost and V. S. C. Yeh, "A Dinuclear Zn Catalyst for the Asymmetric Nitroaldol (Henry) Reaction," Angewandte Chemie International Edition, Vol. 41, 2002, pp. 861-863

[39] C. L. Zhou, Y. Q. Zhou and Z. Y. Wang, "Henry Reaction in Aqueous Media: Chemoselective Addition of Aldehydes," Chinese Chemical Letters, Vol. 14, 2003, pp. 355-358.

[40] H. J. Bestmann, "Old and New Ylid Chemistry," Pure and Applied Chemistry, Vol. 52, 1980, pp. 771-788. doi:10.1351/pac198052040771 